\title{
Breastfeeding Practices among Mothers at Birth and at 6 Months in Urban Areas of Delhi-Ner, India
}

\author{
Urvashi Mehlawat ${ }^{1}$, Seema Puri ${ }^{1 *}$, Tejmeet Kaur Rekhi ${ }^{1}$ \\ ${ }^{1}$ Department of Food and Nutrition, Institute of Home Economics, University of Delhi, \\ New Delhi 110016, India
}

\begin{abstract}
The objective of the present was to potray the breastfeeding practices followed by breastfeeding mothers, at birth and at 6 months, in urban areas of Delhi-National Capital Region. For this, 185 dyads of motherinfant aged 6 months were selected from Pediatric Outpatient Department of a government and a private hospital. A questionnaire-cum-interview was designed to collect the participants' information on breastfeeding practices. It was found that only $29.7 \%$ infants had early initiation of breastfeeding despite the high $(78.9 \%)$ institutional deliveries. Around $40.5 \%$ infants were given feeds apart from breast milk, mainly infant formula $(81.3 \%)$ at the hospital after birth. There were $13 \%$ infants who received pre-lacteal feeds, mainly as a traditional family custom. The practice of exclusive breastfeeding for first six months was followed by $62.2 \%$ mothers. Complementary feeding or top feeding was received by $71.9 \%$ infants, but only $45.1 \%$ mothers initiated complementary foods at the recommended age of 6 months. It can be concluded that in the urban areas of India breastfeeding practices remains poor even after rigorous work done for promotion and protection of breastfeeding. Hence strong institutional care and support for breastfeeding is required at birth and efficient counseling for appropriate feeding of the infant is needed to intensify breastfeeding.
\end{abstract}

Keywords: breastfeeding, breast milk, complementary feeding

\section{INTRODUCTION}

Breastfeeding practices like initiation of breastfeeding within one hour of birth and exclusive breastfeeding for the first six months of life have immense public health importance (Gupta et al. 2019). Breastfeeding has nutritional, immunological, behavioral and economic benefits and also provide desirable mother infant bonding (Shili et al. 2012). Breastfeeding offers adequate nutrition for the baby as well as build up the bond between mother and their baby (Pangestuti 2018). The beneficial effects of breastfeeding depend on time of breastfeeding initiation, its duration and the age at which the breastfed child is weaned (Victoria et al. 1987). The Lancet 2013 report showed that optimal breastfeeding has a greater role in averting $13 \%$ of all deaths under the age of 5 years in developing countries (UNICEF 2015). Optimal breastfeeding practices are potentially one of the top interventions for reducing under-five mortality and is essential for the achievement of many of the newly launched Sustainable Development Goals by 2030, as it can help to improve child and maternal health, nutrition, economy, intelligence, and human capital, while reducing inequalities (Sultania et al. 2019).

Colostrum, the milk secreted in the first 2-3 days after delivery, acts as the first immunization right after birth for the newborn. Colostrum is rich in white cells and antibodies, especially sIgA, and it contains a larger percentage of protein, minerals and fat-soluble vitamins (A, E, and $\mathrm{K}$ ) than later milk (Polineni et al. 2016). Hence early initiation of breast feeding is essential for the infant to avail of the benefit of colostrum.

Exclusive Breastfeeding (EBF) is defined as giving no food to the infant except breast milk except oral rehydration solution, vitamins, minerals or medicines (WHO 2003). EBF for the first six months of life is the cornerstone of optimum infant nutrition (WHO 2008). It reduces the risk of the infant to experience diarrheal diseases (Ogbo et al. 2017; Ogbo et al. 2017; Victoria et al. 2016; Ogbo et al. 2018), upper respiratory tract infections, obesity in later life, and EBF could also improve the neurocognitive functions of the child (Victoria et al. 2016). Breastfed babies have less chance of allergies, asthma and eczema. Evidence suggests that exclusive breastfeeding for at least two months

\footnotetext{
"Corresponding Author: tel: +91-981000322, email: dr.seemapuri@gmail.com
} 
protects susceptible children from Type I Insulin Dependent Diabetes Mellitus (IDDM) (Polineni et al. 2016).

In ancient time, breastfeeding was the only source of feeding of newborn, but during industrialization, urbanization and modernization, this practice has gradually declined (MoHFW, GOI 2013). Studies have shown that EBF rates were influenced by mother's education, age, and employment; infant's age, sex; access to healthcare; neighborhood of residence; and exposure to mass media or counselling (Martines et al. 1989; Kimani-Murage et al. 2011; Tamiru et al. 2013, Setegn et al. 2012; Mekuria \& Edris 2015).

Though there has been an improvement in the breastfeeding status in India over decades due to strengthening of policies, effective capacity building initiatives, community-based actions and strategic mass media communication (Aguayo et al. 2016), further progress is necessary as highlighted in National Health and Family Survey (NFHS)-4 (2015-16). Data shows that only 41.6 percent children are breastfed within first hour of birth in spite of a substantial increase in the rates of institutional deliveries from 38.7 per cent (NFHS-3) to 78.9 per cent (NFHS- 4) during a span of ten years. Also, nearly half $(45.1 \%)$ the children under six months of age are not exclusively breastfed for the first six months (IIPS 2017). NFHS- 4 also shows that $21 \%$ newborns receive pre-lacteal feeds and about $22 \%$ babies are born with low birth weight, who need extra support. Many of the current institutional birth in India were done in private facilities. While, evidence suggest that introduction of infant formula in private health facilities is a common practice (Gupta \& Thankur 2018).

Thus, to achieve optimum breastfeeding status, it becomes imperative to first understand the breastfeeding practices followed by mothers and the healthcare providers. So, the objective of the present study is to investigate the breastfeeding practices followed by breastfeeding mothers when their babies were at birth and at 6 months in Urban Delhi-NCR.

\section{METHODS}

\section{Design, location, and time}

The present study was a descriptive crosssectional study undertaken at the Outpatient
Pediatric Department (OPD) of a private clinic and Government Hospital in Gurugram (NCR). The data was collected from March 2017 to December 2017.

\section{Sampling}

A total of 185 mother-infant (6 months) dyads attending Pediatric OPD of two sites i.e. 100 from a private clinic, Gurugram and 85 from public hospital, of Gurugram were selected purposively due to their high OPD rate to assess the breastfeeding practices followed by mothers when their babies were at birth and at 6 months in Delhi-NCR. Infants aged less than or more than $6 \pm 0.5$ months, infants suffering from any severe chronic disease or disorder, twins, low birthweight, pre-term and, infants never breastfed were not included in the study.

\section{Data collection}

The tool for data collection used was a detailed questionnaire followed by structured interview designed to record the respondents' socio-demographic profile, infants' details, maternal details, information on breastfeeding practices i.e. early initiation of breastfeeding, top feeds and pre-lacteals given, exclusive breastfeeding for six months, continued breastfeeding, bottle feeding and initiation of complementary feeding. Retrospective data was collected to get information about early breastfeeding practices of mothers around birth.

Participant information sheet was given to the enrolled respondents and a written informed consent was obtained before conducting the interview. The participant information sheet was read out to mothers who were illiterate, and their thumb prints were taken on informed consent sheet. Written permission was also obtained from both of the study sites i.e. private clinic, Gurugram and District Civil Hospital, Gurugram for conducting the study. Ethical clearance (IHE/2017/Ethics/019) was granted from the Institutional Ethics Committee of the Institute of Home Economics, University of Delhi.

\section{Data analysis}

Data coding and data entry was done using in MS Excel. Frequency and percentages were calculated for the participants' sociodemographic profile, infants' details, maternal details, immunization details, IYCF practices. 
Mean and standard deviations were calculated for continuous variables.

\section{RESULTS \& DISCUSSION}

\section{Socio-demographic details}

Infants. The results of the present study highlighted that of the total 185 infants, $63.7 \%$ were males and $36.2 \%$ were females respectively, with majority (92.4\%) being Hindus. The mean (SD) age of the infants was $6 \pm 0.52$ months and the mean (SD) birth weight was $2.8 \pm 0.54 \mathrm{~kg}$. No significant difference $(\mathrm{p}=0.13)$ was found between the birth weight of infants from Civil Hospital and private hospital clinic. Most (53\%) of the infants were delivered at Government Hospital followed by $44.3 \%$ at Private hospital. Regarding the mode of delivery, $62.7 \%$ were vaginal deliveries while $37.2 \%$ were C-section deliveries. Nearly half $(46.5 \%)$ of the infants were the first-born child (Table 1).

Mothers. Maternal age ranged from 17 to 38 years and nearly half $(55.4 \%)$ the mothers were between the age of 23 to 27 years. Twenty-six per cent mothers were graduates followed by $22.7 \%$ who had senior secondary level of education. Only $12.4 \%$ were illiterate. Majority $(91.4 \%)$ of the mothers were housewives. There were $48.1 \%$ mothers who had only one child and $36.8 \%$ with two children. Amongst all mothers, 56.2\% belonged to joint families but more mothers i.e. $61.2 \%$ attending civil hospital had a nuclear family as compared to $29 \%$ mothers attending private hospital. This could be because mothers attending Government Hospital originally belonged to other states and settled in DelhiNCR with their husband and children. More than half $(55.1 \%)$ of the participants had four to six members in the family (Table 2).

\section{Early breastfeeding practices}

Early initiation of breastfeeding was found to be sub-optimum in the present study (Figure 1). Around one-third (29.7\%) of the infants were fed breastmilk within one hour of the birth. Among the mothers attending pediatric OPD of private clinic, only $22 \%$ reported to feed their infant with breastmilk within first one hour of birth while $38.8 \%$ mothers from civil hospital did so. In the case of C-section deliveries, $87 \%$ of the infants first received breastmilk after two or more days. Regarding colostrum feeding, $94.1 \%$ of infants
Table 1. Characteristics of infants 6 months of age visiting pediatric Outpatient Pediatric Department (OPD) of private clinic and civil hospital, Gurugram

\begin{tabular}{|c|c|c|}
\hline Characteristic & $\begin{array}{l}\text { Frequency } \\
(\mathrm{n}=185)\end{array}$ & Percentage \\
\hline \multicolumn{3}{|l|}{ Gender } \\
\hline Males & 118 & 63.7 \\
\hline Females & 67 & 36.2 \\
\hline \multicolumn{3}{|l|}{ Religion } \\
\hline Hindu & 171 & 92.4 \\
\hline Muslim & 13 & 7 \\
\hline Sikh & 1 & 0.5 \\
\hline \multicolumn{3}{|l|}{ Place of delivery } \\
\hline At home & 5 & 2.7 \\
\hline Private hospital & 82 & 44.3 \\
\hline Government hospital & 98 & 53 \\
\hline \multicolumn{3}{|l|}{ Type of delivery } \\
\hline Vaginal & 116 & 62.7 \\
\hline C-section & 69 & 37.2 \\
\hline \multicolumn{3}{|l|}{ Birth Order } \\
\hline First & 89 & 48.1 \\
\hline Second & 68 & 36.8 \\
\hline Third & 22 & 12 \\
\hline Fourth & 6 & 3.2 \\
\hline
\end{tabular}

received it after birth with $92.4 \%$ from private hospital and 91\% from civil hospital. Two-third $(69.7 \%)$ of the mothers fed it because it was suggested by the doctor/health worker followed by only $28 \%$ reported feeding it as it is good for the immunity of the baby. Half the mothers who did not feed colostrum to their babies followed the advice of the doctors/health workers, who suggested them not to give their colostrum to their baby. Only $13 \%$ infants received prelacteals such as honey, ghutti and it is mostly as a traditional practice followed in the family $(75 \%)$. About $45 \%$ of the infants were given feeds other than breastmilk, infant formula being the most commonly $(81.3 \%)$ given at the hospital right after birth. When analyzed according to the place 
Table 2. Socio-demographic characteristics of mothers visiting pediatric Outpatient Pediatric Department (OPD) of private clinic and civil hospital, Gurugram

\begin{tabular}{|c|c|c|}
\hline Characteristic & $\begin{array}{c}\text { Frequency } \\
(\mathrm{n}=185)\end{array}$ & Percentage \\
\hline \multicolumn{3}{|l|}{ Age (years) } \\
\hline $17-22$ & 36 & 19.5 \\
\hline $23-27$ & 97 & 52.4 \\
\hline $28-32$ & 41 & 22.2 \\
\hline $33-37$ & 11 & 6 \\
\hline \multicolumn{3}{|l|}{ Education } \\
\hline lliterate & 23 & 12.4 \\
\hline Primary school & 7 & 3.8 \\
\hline Middle school & 21 & 11.4 \\
\hline Secondary school & 27 & 14.6 \\
\hline Senior secondary school & 42 & 22.7 \\
\hline Graduation & 48 & 26 \\
\hline Post-graduation & 27 & 14.6 \\
\hline \multicolumn{3}{|l|}{ Livelihood } \\
\hline Working & 16 & 8.6 \\
\hline Non-working & 169 & 91.4 \\
\hline \multicolumn{3}{|l|}{ Parity } \\
\hline 1 & 89 & 48.1 \\
\hline 2 & 68 & 36.8 \\
\hline$>2$ & 28 & 15.1 \\
\hline \multicolumn{3}{|l|}{ Type of family } \\
\hline Nuclear & 81 & 43.8 \\
\hline Joint & 104 & 56.2 \\
\hline \multicolumn{3}{|l|}{ Size of family } \\
\hline$<4$ & 47 & 25.4 \\
\hline $4-6$ & 102 & 55.1 \\
\hline$>6$ & 36 & 19.5 \\
\hline
\end{tabular}

of birth, 36.5\% infants from Government hospital and $53 \%$ infants delivered in private hospital received top feeds such as infant formula, animal milk, pulse water.

\section{Breastfeding practices at 6 months}

Majority of the mothers (92.4\%) were breastfeeding their child at the age of 6 months and only $7.5 \%$ mothers discontinued it by 5 months of age. Insufficiency of breastmilk was the primary reason for discontinuing breastfeeding as reported by $71.4 \%$ mothers from both private clinic and Government hospital who no longer breastfeeding. There were $46.2 \%$ mothers who were feeding breastmilk to their child for more than 12 times a day. When asked about the sufficiency of breastmilk for fulfilling all nutritional requirements of the infant at 6 months, $68.6 \%$ mothers suggested that breastmilk alone is not enough for the proper growth and development of the baby and hence foods other than breastmilk needs to be given to the child (Table 3).

\section{Exclusive breastfeeding and complementary feeding}

Table 4 highlights the exclusive breastfeeding and complementary feeding status of the mothers. Overall $62.2 \%$ infants were exclusively breastfed for the first 6 months or beyond. Almost similar percentage of mothers i.e. $61 \%$ from both private clinic and $63.5 \%$ from civil hospital reported exclusively breastfeeding their child. Complementary feeding/top feeding was initiated by $71.8 \%$ mothers mostly because they felt that the baby was hungry even after breastfeeding. But only $32.4 \%$ mothers initiated complementary feeding at an appropriate age of 6 months. Bottle feeding was reported among $23.8 \%$ infants. When inquired about the foods

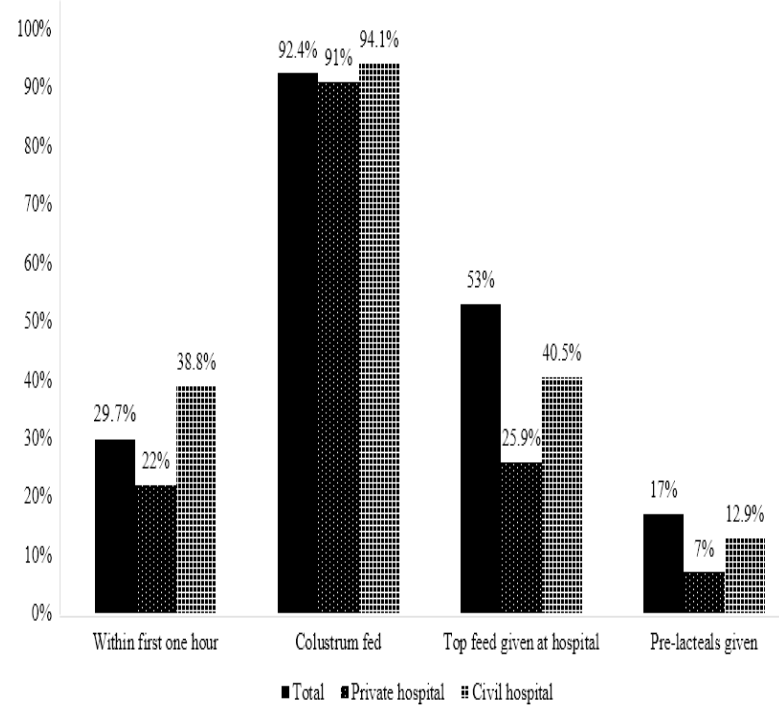

Figure 1. Early breastfeeding practices amongst mothers of infants 6 months of age 
Table 3. Breastfeeding practices amongst mothers of infants at 6 months

\begin{tabular}{lcc}
\hline \multicolumn{1}{c}{ Breastfeeding Practices (BF) at 6 months } & Frequency $(\mathrm{n}=185)$ & Percentage \\
\hline Continued BF at 6 months & 171 & 92.4 \\
Frequency of BF/day & $(\mathrm{n}=171)$ & $(\mathrm{n}=171)$ \\
$<3$ times & 2 & 1.2 \\
3-6 times & 7 & 4.1 \\
6-9 times & 30 & 17.5 \\
9-12 times & 53 & 31 \\
$>$ 12 times & 79 & 46.2 \\
Duration of BF before discontinuation & $(\mathrm{n}=14)$ & $(\mathrm{n}=14)$ \\
$<3$ months & 4 & 28.6 \\
3-5 months & 10 & 71.4 \\
${ }^{*}$ Reasons to stop BF & $(\mathrm{n}=14)$ & $(\mathrm{n}=14)$ \\
Age of the infant & 1 & 7.1 \\
Child stopped himself/herself & 4 & 28.6 \\
Insufficient breast milk & 10 & 71.4 \\
Mother was sick & 1 & 7.1 \\
Mother resumed work & 1 & 7.1 \\
Breast milk sufficient at 6 months (mother's perception) & & 31.3 \\
Yes & 58 & 68.6 \\
No & 127 & \\
\hline
\end{tabular}

*Multiple responses

given to the infant in the past 24 hours, $35.7 \%$ infants received breastmilk only, $34.6 \%$ infants received semi-solid foods and $27.6 \%$ infants were given animal-source milk. These foods were mainly given as the mothers felt that the baby was hungry or thirsty, advised by doctor/ health worker or by mother/mother-in-law.

Appropriate feeding is crucial for the healthy growth and development of the infants. Breastmilk is the natural first food for babies. It continues to provide upto half or more of the child's nutritional needs during the second half of the first year, and upto one third during the second year of life (WHO 2009). In the present study few early breastfeeding practices were found to be sub-optimal even after $97.3 \%$ institutional births. Provision of mother's breast milk to infants within an hour of birth is referred to as "Early Initiation of Breastfeeding" (EIBF).
This ensures that the colostrum or "the first milk," which is rich in protective factors, is given to the infants immediately after delivery. In developing countries like India, EIBF could save about 1.45 million lives a year, attributed to various infections (Lauer et al. 2006). Early initiation of breastfeeding was as low as $22 \%$ in the present study. Shili and co-authors conducted a study in rural areas of Uttarakhand to know breast feeding practices of mothers and to strengthen these practices among 500 mother infant dyads. They also found that only $21.37 \%$ of the infants received breastmilk within first one hour of birth (Shili et al. 2012). Major barriers to early initiation of breast feeding includes lack of awareness regarding proper technique of breastfeeding and benefits of colostrum, breast abnormality like inverted/retracted nipples, obstetric/neonatal complications requiring 
Table 4. Exclusive breastfeeding and complementary feeding practices amongst mothers of infants at 6 months

\begin{tabular}{lcc}
\hline \multicolumn{1}{c}{ Indicators } & $\begin{array}{c}\text { Frequency } \\
(\mathrm{n}=185)\end{array}$ & Percentage \\
\hline $\begin{array}{l}\text { Exclusive breastfeeding untill } \\
6 \text { months or beyond }\end{array}$ & 115 & 62.2 \\
$\begin{array}{l}\text { Children receiving } \\
\text { complementary feeding (CF) }\end{array}$ & 133 & 71.8 \\
$\begin{array}{l}\text { Initiation of CF at } 6 \text { months } \\
\text { Bottle feeding }\end{array}$ & 60 & 32.4 \\
\hline
\end{tabular}

specialized care, and cultural practices like giving pre-lacteals and gender discrimination (Majral \& Silan 2016). Breast feeding initiation can be particularly delayed for infants born by caesarean section. Prospective cohort studies in India have shown that infants born by caesarean section were almost four times less likely to initiate breast feeding within 1 hour of birth than infants born by vaginal delivery (Patel et al. 2015). Only $13 \%$ infants delivered by $\mathrm{C}$-section received breastmilk within first one hour of the birth. This indicates that adequate support is not provided to mother during caesarean section delivery which acts as a barrier in early initiation of breastfeeding. However, colostrum was given to majority $(92.4 \%)$ of the infants which is an improvement based on the Infant and Young Child Feeding (IYCF) recommendations. Similar findings were reported by Polineni et al. where 96.3\% mothers fed colostrum to the infants (Polineni et al. 2016). But 69.7\% mothers gave colostrum as it was suggested by the doctor/health which reflects that there is a lack of knowledge among mothers about the benefits of colostrum feeding in the present study. Pre-lacteals such as honey, ghutti was given to only $13 \%$ infants mainly as a traditional practice in the family which can be considered as a success in IYCF counseling in India. On contrary to this, Shili and associates reported that pre-lacteals such as sugar water, honey and gripe water were given to $61.8 \%$ infants (Shili et al. 2012).

While continued breastfeeding at 6 months was observed among $92.4 \%$ mothers, exclusive breastfeeding was practiced by $62.2 \%$ mothers which is more than the figure $(54.9 \%)$ reported in NFHS-4 (IIPS 2017). The results are similar to another study carried out by Kumari et al, in Telangana where exclusive breastfeeding was followed by $60.6 \%$ mothers (Kumari et al. 2017). In another study in Karnataka only $40 \%$ mothers were exclusively breastfeeding their babies (Madhu et al. 2009). The most common reason seen for discontinuing exclusive breastfeeding before six months is insufficiency of breastmilk as perceived either by the mother herself or the family members.

In the present study $71.8 \%$ infants received complementary foods/top milk but only $32.4 \%$ received them at the appropriate age of six months. Either early or late introduction of the complementary foods was observed. This shows the lack of knowledge among the mothers regarding appropriate age of initiation of complementary feeding and to certain extent the pressure from family members as the majority of the mothers belonged to joint family. The insufficiency of breast milk was a major concern for the grandmothers who recommended their daughter/ daughter-in-law to start giving the child other foods before six months (Fjeld et al. 2008). Likewise Aggarwal et al. reported that only $17.5 \%$ mothers started complementary feeding at the recommended time (Aggarwal et al. 2008). On the other hand among 200 mothers, $77.5 \%$ started complementary feeding at the recommended age of six months as highlighted in another hospital based study in Mangalore (Rao et al. 2011)

\section{CONCLUSION}

It can be concluded that the present study focuses on the need of support provided for early initiation of breastfeeding to the mothers at the health facility especially for those who had caesarean section deliveries. The practice of giving top feeds at the hospital right after the birth should be discouraged and a more stringent monitoring system should be developed to prevent these malpractices. Though there seems to be an improvement in exclusive breastfeeding, further education and awareness should be provided during ante-natal and post-natal counselling to mothers as well as the family members regarding the benefits of early and exclusive breastfeeding and continued breastfeeding till two years of age 
as well as the proper time for complementary feeding initiation.

\section{ACKNOWLEDGEMENTS}

Th authors would like to acknowledge all the participants for giving consent to be a part of this study. The authors have no conflict of interest.

\section{AUTHOR DISCLOSURES}

The authors have no conflict of interest.

\section{REFERENCES}

Aggarwal A, Verma S, Faridi MMA, Dayachand. 2008. Complementary feeding reasons for inappropriateness in timing, quantity and consistency. Indian j Pediatr 75(1):49-53. https://doi.org/10.1007/s12098-008-00069.

Aguayo VM, Gupta G, Singh G, Kumar R. 2016. Early initiation of breast feeding on the rise in India. BMJ Glob Health 1(2):e000043. doi: 10.1136/bmjgh-2016-000043.

Fjeld E, Siziya S, Katepa-Bwalya M, Kankasa C, Moland KM, Tylleskar T. 2008. 'No sister, the breast alone is not enough for my baby' A qualitative assessment of potentials and barriers in the promotion of exclusive breastfeeding in southern Zambia. Int Breastfeed J 3(1): 26. https:// doi.org/10.1186/1746-4358-3-26.

Gupta A, Dadhich J, Ali SM, Thakur N. 2019. Skilled counseling in enhancing early and exclusive breastfeeding rates: An experimental study in an urban population in India. Indian Pediatr 56(2):114-118. https://doi.org/10.1007/s13312-0191482-x.

Gupta A, Thakur N. 2018. Infant and young feeding practices in India: Current status and progress towards SDG targets. Proc Indian Natl Sci Acad 84(4): 853-865. https://doi. org/10.16943/ptinsa/2018/49440.

[IIPS] International Institute for Population Sciences and Macro International. 2017. National Family Health Survey (NFHS-4), 2015-2016: India. Mumbai (IN): IIPS.

Kimani-Murage EW, Madise NJ, Fotso JC, Kyobutungi C, Mutua MK, Gitau TM,
Yatich N. 2011. Patterns and determinants of breastfeeding and complementary feeding practices in urban informal settlements, Nairobi Kenya. BMC Public Health 11(1):396. https://doi. org/10.1186/1471-2458-11-396.

Kumari SMV, Rani GS, Rao BB. 2017. A study on infant feeding practices in rural areas of Warangal district, state of Telangana, India. Int J Contemp Med Res 4(4):789-791.

Lauer JA, Betrán AP, Barros AJ, de Onís M. 2006. Deaths and years of life lost due to suboptimal breast-feeding among children in the developing world: A global ecological risk assessment. Public Health Nutr 9(6):673-685. https://doi. org/10.1079/PHN2005891.

Madhu K, Chowdary S, Masthi R. 2009. Breast feeding practices and newborn care in rural areas: A descriptive cross-sectional study. Indian J Community Med 34:243-246. doi: 10.4103/0970-0218.55292.

Majral JP, Silan VK. 2016. Barriers to early initiation and continuation of breastfeeding in a tertiary care institute of Haryana: A qualitative study in nursing care. J Clin Diagn Res 10(9): LC16-LC20. doi: 10.7860/JCDR/2016/19072.8559.

Martines JC, Ashworth A, Kirkwood B. 1989. Breast-feeding among the urban poor in southern Brazil: reasons for termination in the first 6 months of life. Bull World Health Organ 67(2):151-61.

Mekuria G, Edris M. 2015. Exclusive breastfeeding and associated factors among mothers in Debre Markos, Northwest Ethiopia: A cross-sectional study. Int Breastfeed J 10:1. ttps://doi.org/10.1186/ s13006-014-0027-0.

[MoHFW] Ministry of Health and Family Welfare, GOI. 2013. Guidelines for enhancing Infant and Young Child Feeding Practices. http://nrhm.gov.in/images/pdf/ programmes/child-health/guidelines/ Enhancing-optimal-IYCF-practices.pdf. [Accessed 5th Jan 2015].

Ogbo FA, Agho K, Ogeleka P, Woolfenden S, Page A, Eastwood J. 2017. Infant feeding practices and diarrhoea in sub-Saharan African countries with high diarrhoea mortality. Plos One 12(2):e0171792. doi:10.1371/journal.pone.0171792. 
Ogbo FA, Nguyen H, Naz S, Agho KE, Page A. 2018. The association between infant and young child feeding practices and diarrhoea in Tanzanian children. Tropical Medicine and Health 46(2):1-9. doi 10.1186/s41182018-0084-y.

Ogbo FA, Page A, Idoko J, Claudio F, Agho KE. 2016. Diarrhoea and suboptimal feeding practices in Nigeria: evidence from the national household surveys. Paediatr Perinat Epidemiol 30:346-55. https://doi. org/10.1111/ppe.12293.

Pangestuti, DR. 2018. Nutritional status of exclusive compared to non exclusive breastfeeding mother. J Gizi Pangan 13(1):11-16. https://doi.org/10.25182/ jgp.2018.13.1.11-16.

Patel A, Bucher, S, Pusdekar Y, Esamai F, Krebs NF, Goudar SS, Chomba E, Garces A, Pasha O, Saleem S, Kodkany BS, et al. 2015. Rates and determinants of early initiation of breastfeeding and exclusive breast feeding at 42 days postnatal in six low and middle-income countries: A prospective cohort study. Reproductive Health 12(Suppl 2):S10. https://doi. org/10.1186/1742-4755-12-S2-S10.

Polineni V, Boralingiah P, Kulkarni P, Manjunath R. 2016. A comparative study of breastfeeding practices among working and non-working women attending a tertiary care hospital, Mysuru. Ntl J Community Med 7(4):235-240.

Rao S, Swathi PM, Unnikrishnan B, Hegde A. 2011. Study of complementary feeding practices among mothers of children aged six months to two years - A study from coastal South India. Australas Med J 4(5):252-257. doi:10.4066/ AMJ.2011.607.

Setegn T, Belachew T, Gerbaba M, Deribe K, Deribew A, Biadgilign S. 2012. Factors associated with exclusive breastfeeding practices among mothers in Goba district, south East Ethiopia: A cross-sectional study. Int Breastfeed J 7(1):17. https://doi. org/10.1186/1746-4358-7-17.

Sultania P, Agrawal NR, Rani A, Dharel D, Charles R, Dudani R. 2019. Breastfeeding knowledge and behavior among women visiting a tertiary care center in India: A cross-sectional survey. Ann Glob Health. 85(1):64. doi: 10.5334/aogh.2093.

Tamiru D, Aragu D, Belachew T. 2013. Survey on the introduction of complementary foods to infants within the first six months and associated factors in rural communities of Jimma Arjo. International Journal of Food Sciences and Nutrition 2(2):77-84. doi: 10.11648/j.ijnfs.20130202.18.

[UNICEF] United Nations Children's Fund. 2015. Breastfeeding. http://www.unicef.org/ nutrition/index 24824.html. [Accessed 24th January 2019].

Victoria CG, Bahl R, Barros AJD, França GVA, Horton S, Krasevec J, Murch S, Sankar MJ, Walker N, Rollins NC. 2016. Breastfeeding in the $21 \mathrm{st}$ century: Epidemiology, mechanisms, and lifelong effect. The Lancet 387(10017):475-90. https://doi. org/10.1016/S0140-6736(15)01024-7.

Victoria CG, Vaughan JP, Lombardi C, Fuchs SMC, Gigante LP, Smith OG, Nobre LC, Teixeira AB, Moreira LB, Barros FC 1. 1987. Evidence for protection by breastfeeding against infant deaths from infectious diseases in Brazil. The Lancet 330(8554):319-322. https://doi. org/10.1016/S0140-6736(87)90902-0.

Shili V, Parul S, Kanpal SD, Jayanti S, Anurag S, Vipul N. 2012. A community based study on breastfeeding practices in a rural area of Uttarakhand. National Journal of Community Medice 3(2):283-287.

[WHO] World Health Organization. 2003. Global Strategy for Infant and Young Child Feeding. Geneva (CH): World Health Organization.

[WHO] World Health Organization. 2008. Indicators for Assessing Infant and Young Child Feeding Practices. Geneva $(\mathrm{CH})$ : World Health Organization.

[WHO] World Health Organization. 2009. Breastfeeding.http://www.who.int/ entity/child_adolescent_health/topics/ prevention_care/child/nutrition/ breastfeeding/en. [Accessed 14th October 2009]. 